\title{
Lectura del texto audiovisual en la sociedad hipermedial
}

\section{Reading of the audiovisual text in the hypermedial society}

*Eufemia Figueroa Corrales; Rosalina Soler Rodríguez¹; Miguel Ángel Franco Noa².

${ }^{1}$ Universidad de Oriente. Santiago de Cuba, ${ }^{2}$ Dirección Municipal de Educación. Santiago de Cuba

*eufemia@uo.edu.cu

Fecha de recepción: 15/11/2017

Fecha de aceptación: 08/12/2017

Publicado: 24/12/2017

\section{Resumen}

El trabajo tiene como objetivo proponer un método para la leer el texto audiovisual cinematográfico en la sociedad hipermedial en la que coexisten nativos y emigrantes digitales. La experiencia se lleva a cabo en carreras de perfil pedagógico de la Universidad de Oriente a partir del estudio de caso atendiendo a la labor social de este profesional que favorece y promociona la lectura, en las comunidades desde contextos tanto virtuales como presenciales y que aprende desde la posición de estudiante espectador-lector.

Palabras clave: texto audiovisual, sociedad hipermedial, nativos y emigrantes digitales.

\begin{abstract}
This piece of work has the aim of proposing a method for reading the movie audiovisual texts in the hipermedia society in which there co-exist native and immigrant digitals. The experience is being carried out in pedagogical careers of the University of Oriente starting from the study of the case, taking into account the social work that this professional offers and promotes reading, in the communities since the context either visual or present and he also learns since the position of viewer-readers students.
\end{abstract}

Keywords: audiovisual texts, hipermedia society, native and immigrant digitals, viewer-readers students. 


\section{Introducción}

La observación a la realidad da cuenta de que la lectura y comprensión de textos como dominio cognitivo, se mantiene relacionada con la lectura del texto literario, aspecto que, desde la opinión de los autores de este trabajo marca una insuficiencia que limita la inclusión de textos con códigos diversos: icónicos, icónicos-verbales y audiovisuales. Además, se revela una contradicción a partir de las exigencias de la sociedad actual en la que la audiovisualidad promociona la generalidad de lo que gusta al público heterogéneo, por lo que urge enseñar a leer y comprender en la multimodalidad textual. Para este propósito se utilizaron métodos del orden teórico y técnicas empíricas.

De los métodos teóricos, se enfatizó en el análisis -síntesis, así como en el sistémico estructural funcional y como técnicas empíricas el estudio de caso y la observación. Los métodos empleados revelaron, objetivas contradicciones y la necesidad de incorporar un método para direccionar la lectura y comprensión del texto cinematográfico, de manera contextualizada con el texto literario y con la realidad en la que la audiovisualidad ocupa un lugar cimero para la comunicación intersubjetiva entre nativos y emigrantes digitales.

Del análisis teórico relacionado con el proceso de lectura y comprensión del texto cinematográfico surgieron propuestas que coadyuvan a la dirección de los procesos aludidos. Emerge el método de comprensión plurisignificativa y sus respectivos procedimientos los que son garantes de una lectura crítico-reflexiva, comprensiva y adecuada a la diversidad de códigos textuales discursivos de las nuevas realidades.

\section{Desarrollo}

Actualmente se lee de diversas modalidades textuales en consecuencia, autores como Cassany, D.( (s/f) Rodríguez, L.(2010) entre muchos se han preocupado por Cienc. Soc. y Econ. UTEQ. 2017. 1(2): 125-144 126 
abordar la temática de la lectura desde diversas perspectivas y han marcado características que distinguen el proceso aludido en este Siglo XXI en tanto vivir hoy, la lectura se valoriza a partir del cocimiento del signo en su diversidad sin asirse al lingüístico de manera única, lo que demanda seguir la iconicidad, el simbolismo y muy especialmente, la imagen audiovisual a la cual acceden todas las generaciones coexistentes.

De acuerdo con Cassany,D. (s/f) hoy debe enseñarse a leer desde diferentes puntos de vista entre los que se hallan: la hipertextualidad (el aula virtual, el software); Intertextualidad (entre textos de diferente naturaleza sígnica); el enlace electrónico; los géneros electrónicos; los emoticonos (texto icónico y a veces combinado con el verbal) sin obviar el dominio del léxico y de la gramática para la lectura en correo electrónico y chat.

Asimismo se refiere a la lectura desde la electrónica como la que favorece la integración de otros sistemas de representación del conocimiento en un único formato por lo que las propiedades discursivas no solo se le atribuyen a las letras, ahora se adicionan fotos, vídeo, audio, reproducción virtual, etc.

Por lo antes expuesto se declara que el desarrollo de la lectura en este Siglo XXI debe proyectarse desde una dimensión contextualizada a la realidad de las generaciones más jóvenes con énfasis en aquellas que liderarán los procesos de enseñanza aprendizaje en el futuro mediato.

Se conoce que el hombre actual está mucho más incentivado por lo audiovisual dado a la tenencia del móvil, del Tablet, de la PC y del televisor híbrido, entre muchos que dan cuenta de modernidad. Esta situación, aleja a las personas de la nueva generación del libro impreso y da créditos a lo digital o digitalizado. De manera que en el proceso de formación del pedagogo se hace necesaria la introducción de nuevos incentivos que 
lo preparen para acceder a la lectura del audiovisual como muestra de texto multisígnico.

De acuerdo con lo antes señalado se significa que para leer hoy, debe reconocerse a la semiótica como teoría ligada al proceso de lectura y comprensión, pues esta disciplina no solo tiene por objeto de estudio -qué son los signos, su naturaleza, sus clases y tipossino que además, se ocupa de la función de estos como instauradores de sentido y facilitadores de relaciones comunicativas; de modo que es lícito reconocer la necesidad de una orientación sociosemiótica en la didáctica del proceso de lectura y comprensión del texto cinematográfico, modalidad en la que confluye el signo en su diversidad: ícono, símbolo e indicio y que de lo que se trata es de conducir al estudiante espectadorlector hacia el conocimiento y distinción del signo y de los plurisignificados que emergen de su análisis a partir del establecimiento de una correcta interacción subjetiva con el intra y extratexto sin la cual sería imposible el intercambio sujeto-objeto-sujetosujeto.

Se subraya, la importancia del estudiante espectador-lector, el que a partir de la orientación detallada del profesor y de los conocimientos que posee, podrá leer y comprender lo que se comunica a través de los diferentes sistemas de signos presentados por los emisores desde los procesos codificación (construcción de significados) y decodificación (comprensión del texto cinematográfico en este caso).

La aproximación a lo cinematográfico como texto, requiere de la cognición de la multiplicidad de microtextos que lo conforman para la decodificación de signos a partir de la naturaleza semiótica de la imagen audiovisual, de su carácter sugerente; razones entre muchas, que en opinión de los autores, dan cuenta de que es un dominio cognitivo para especialistas que dirigen el proceso de enseñanza aprendizaje de la lectura y comprensión textual. 
Es así que la lectura y comprensión del texto cinematográfico se entiende en este análisis como un proceso semiótico de acercamiento a la comunicación desde la hermenéutica de los signos utilizados en su distribución que facilitan al estudiante espectador-lector, las herramientas didáctico-metodológicas para establecer relaciones comunicacionales desde las diversas funciones que realizan los códigos, en el texto plurisígnico.

De ahí que para el sujeto aprenda a leer el texto citado se debe proceder a la orientación cognitivo- cinematográfica que se concreta a través de las estrategias cognitivas que el estudiante espectador -lector emplea en relación con los conocimientos acumulados, provenientes de fuentes diversas. A través de la orientación del docente, el estudiante espectador-lector establece nexos entre los conocimientos adquiridos y las nuevas informaciones que le suministra el texto cinematográfico y además, activa los procesos mentales como: abstraer, analizar, comparar, clasificar, organizar, identificar, inferir, recordar, elaborar, que se constituyen en aspectos capaces de desarrollar el proceso de lecturabilidad.

De modo que en este proceso de lectura y comprensión se atiende la transferencia gradual de conocimientos del docente al estudiante espectador-lector, de forma que, en los primeros momentos el docente es el responsable del control de la actividad de aprendizaje, asumiendo el papel de orientador, facilitador y de modelo de la actividad cognitiva y metacognitiva. Esta parte de la orientación como proceso va conduciendo al estudiante espectador-lector hasta la asunción del control y evaluación de su propio conocimiento.

De acuerdo con Mateos (2001) existen procederes que facilitan la transferencia del proceso de aprendizaje como son: la instrucción explícita, la práctica guiada, la práctica cooperativa y la práctica individual. A partir de estos procederes, la asimilación del 
conocimiento transcurre en el intercambio de responsabilidades asumidas frente a la tarea de enseñanza aprendizaje, en un traspaso de influencias cognitivas, progresivo y constante del docente hacia el estudiante.

En ese traspaso de conocimientos se desarrolla el proceso de lectura y comprensión del texto cinematográfico, texto que privilegia el conocimiento de otras manifestaciones del arte como la literatura, la danza, el teatro, la pintura, la arquitectura; la apreciación de obras monumentales. Desde el contacto con el texto cinematográfico, el estudiante espectador-lector, percibe los matices de los sonidos producidos por diferentes instrumentos musicales, reconoce la importancia de la banda sonora en el audiovisual, entre otras posibilidades.

En este sentido, puede aseverase que el gran reto, para el docente, se halla en enseñar al estudiante espectador -lector a leer el texto cinematográfico aun cuando se conoce que es un proceso individual e intrasubjetivo, a ser espectadores-lectores críticos, hábiles para decodificar el lenguaje cinematográfico con presencia de múltiples códigos y a ser conscientes de los mensajes que recibe diariamente desde el contexto sociocultural.

La orientación se concreta en la percepción del texto cinematográfico, cuya clave es leer y descifrar los significados del texto que viene dado por la interacción sincrónica de los códigos cinematográficos, dentro de un contexto secuencial y asociado a una idea. Estos códigos no deben tratarse desde la didáctica, por separado, sin embargo, para el tratamiento de los aspectos cognitivos de los estudiantes, debe declararse que los sonoros se refieren a todo aquello relativo a lo que puede ser escuchado o no, y se subdividen en: sonoros o silentes: voces, ruidos (silencio) y música mientras que los visuales se subdividen en dos grandes grupos: imágenes en movimiento y signos escritos, representados, grabados o graficados. 
De manera que en este proceso interactivo de relación texto cinematográfico/estudiante espectador-lector/contexto) el sujeto que aprende, obtiene, procesa, evalúa y aplica la información a partir de la experiencia previa, de la motivación sobre el contenido del texto y de la cosmovisión, lo que Barthes, R. (2004) denomina su "sistema de expectativas" y Eco, U. (2000) considera su "universo del saber".

En el proceso de referencia, el contacto del estudiante espectador-lector con el texto cinematográfico tratado es una razón innegable, en tanto su eficacia no se reduce a proporcionar información para el aprendizaje ni a procurar distracción o evasión, sino que constituye una vía ético-pedagógica si se aprende para enseñar.

El estudiante espectador-lector se convierte en un procesador de la información que adquiere del texto cinematográfico. De manera que, esta interacción texto- estudiante espectador-lector está mediada por los conocimientos de este, los cuales pueden agruparse en declarativos, procedimentales y condicionales. Los declarativos están asociados a conocimientos sobre el contexto sociocultural en general, la lengua, la escritura y, por consiguiente, acerca de la imagen y del sonido.

Por su parte, los conocimientos procedimentales están relacionados con el cómo progresar en el proceso de lectura y comprensión, desde estrategias de orden cognitivo que permiten al estudiante espectador-lector desarrollar las tareas asignadas. De lo que se deduce que a través de las estrategias cognitivas, este sujeto puede relacionar conocimientos anteriores con informaciones nuevas que le aportan el texto cinematográfico; aspectos que facilitan el ascenso progresivo y cualitativamente superior, por los distintos niveles de lectura y comprensión.

Forman parte de estos procesos mentales habilidades como: observar, abstraer, analizar, comparar, clasificar, organizar, identificar, inferir, recordar, elaborar, los que 
se constituyen en aspectos susceptibles de mejorar y de abordar como contenidos escolares, con el fin de potenciar el desempeño de los profesionales de la educación. En otro orden, los conocimientos procedimentales tienen que ver con la acción y están asociados al cuándo y al porqué mejorar en la tarea; y saber seleccionar la estrategia, los recursos y los procedimientos adecuados para aprender a enseñar a leer y comprender el texto cinematográfico.

Cuando el estudiante espectador-lector es capaz de llegar a la percepción semiocinematográfica, se enfrenta a un subproceso dinámico y complejo que transcurre a partir de la relación del sujeto que orienta(docente) la lectura perceptiva del texto cinematográfico - estudiante espectador-lector; relación en la que el segundo sujeto desarrolla procedimientos cognitivos tales como: recepcionar, codificar y decodificar la información principal y secundaria, identificar códigos que conforman el texto, establecer diferencias entre lo real y lo imaginario y fusionar lo subjetivo con lo objetivo.

La percepción semiocinematográfica es un proceso en el que lo cognitivo, lo comunicativo y lo contextual se complementan en la determinación del contenido esencial del texto y cómo se presenta el contenido (forma). Lo anterior subraya que el estudiante espectador-lector debe desarrollar otros subprocesos cognitivos y metacognitivos para alcanzar el nivel de extrapolación en la comprensión del texto cinematográfico, subprocesos que parten de la recepción y convergen con el análisis y la construcción de significados. Los aspectos que dan cuenta de que se ha producido la percepción semiocinematográfica, son los que se refieren a los procesos cognitivos que favorecen el avance de la memoria, las emociones, los sentimientos y la imaginación en la distinción de la multiplicidad sígnica del texto cinematográfico. 
De hecho, la percepción semiocinematográfica designa el proceso intrasubjetivo que se activa cuando el estudiante espectador-lector entra en contacto con el texto. Este contacto tiene que movilizar nociones previas, socioculturales, disciplinares, entre otras, de forma tal que haya apropiación individual de la información que aporta el texto, tanto explícita como implícitamente o sea que tanto la percepción-lectura como la interpretación son instancias de la comprensión y manifestaciones de la actividad intra e intersubjetiva inherentes al proceso de comunicación entre sujeto (docente)-objeto (texto cinematográfico) sujeto (estudiante espectador-lector).

Se considera que para que la percepción semiocinematográfica del texto sea comprensiva y útil, el docente ofrecerá estrategias específicas que sean aplicables para este tipo de texto. Estas estrategias coadyuvarán al desarrollo de la capacidad para desentrañar la pluralidad significativa de los mensajes del texto, elaborar conjeturas, hacer deducciones, establecer relaciones intra e intertextuales, extrapolar, en fin, demostrar que se pueden atribuir plurisignificados al texto, lejos de reproducir textualmente lo que observan-leen acerca el contenido.

Se subraya que, la percepción semiocinematográfica como vía fundamental a través de la cual el estudiante espectador-lector descubre las particularidades del lenguaje específico y capta el mensaje, identifica detalles que aportan, como la relación tiempoespacio, contenido y forma, entre muchos. En este momento del proceso global, se concede gran importancia a la observación de la combinación imagen-sonido-idea como condición de fundamento para la visualización coherente del texto cinematográfico.

En este proceso perceptivo semiocinematográfico, el estudiante espectador-lector puede decodificar los signos que llegan a través de los analizadores vista y oído. Cuando el analizador vista y oído, en síntesis, facilitan el procesamiento de la información audiovisual se produce el discernimiento sígnico, entendido, como el 
subproceso que se proporciona a nivel intrasubjetivo, en el que se revela la capacidad para desentrañar la estructura interna del texto, captar las ideas, colegir cada uno de los códigos y reconstruir lo que ha significado para sí, sin dejar de ubicarlo en un contexto, subproceso que requiere de:

La atención a los códigos cinematográficos que favorecen la comprensión que la idea proyecta y sirven como punto de partida para la adquisición del nuevo conocimiento.

La capacidad demostrada por el estudiante espectador-lector para ejecutar la segmentación estructural desde el análisis reflexivo y el descubrimiento de la funcionalidad de cada parte, tomando como unidad de observación, la secuencia, dominada por la idea de sucesión (narración) que permite un recorrido sintáctico de la imagen cinematográfica o sea que la desintegración de los códigos de cada secuencia(sintaxis) posibilitará ver cómo aparece articulada, en un proceso de análisis que culmina en síntesis, la relación de los pares dialécticos contenido y forma.

Cuando el estudiante espectador-lector desarrolla el discernimiento sígnico, es capaz de comprender que el texto cinematográfico es sistémico en sí mismo, en tanto en él confluye una variedad sígnica, la cual a su vez tiene, perspectivas de examen en unidades, llamadas microtextos o sea cada uno de las unidades mínimas que se conforman en el intratexto cinematográfico y que son portadoras de significados, que pueden decodificarse sin perder la esencia de totalidad del texto. Figueroa, E. (2007). Se acentúa que, el discernimiento sígnico es un subproceso analítico hermenéutico de indagación que compulsa el hallazgo de la pluralidad de sentidos del texto.

Los citados microtextos, conforman a su vez el gran texto (que incluyen aspectos como géneros y subgéneros, historia y estructura del argumento, y la cuestión del punto de vista o coordenadas espacio-temporales en las que se desarrolla la acción) y pueden ser de carácter connotativo o denotativo. Estos microtextos soportan la sintaxis y la 
esencia semiótica del macrotexto (texto cinematográfico) en tanto ellos son portadores de significados, son coherentes en y entre sí mismos, aspectos que facilitan su análisis individual, sin descuidar el carácter sistémico del texto. Figueroa, E. (2007)

Estos argumentos corroboran que la mayor atención, a partir de la lecto-observación, es para la imagen cinematográfica que se representa en sucesión consecutiva a través de la cual emerge el tema -contenido del mensaje y dan cuenta de que el texto cinematográfico es un enunciado sintético, sugerente y en su estructura contiene como códigos esenciales: idea e imagen cinematográfica, en movimiento perenne.

Para que se desarrolle este subproceso, el estudiante espectador-lector analiza el texto desde la relación con la significación de cada microtexto, desde que es capaz de detenerse en detalles como: título (estructura, significado, relación con el contenido) tonalidades que predominan en el vestuario, en el ambiente, planos más empleados, nivel que alcanza la banda sonora (la música diegética, extradiegética) en función de la comunicación, en la presencia actoral o la presencia del testimoniante si es documental o sea cuando descubre que el signo puede presentarse en forma de ícono, símbolo o indicio.

En el proceso de orientación cognitivo-cinematográfica se manifiesta, cómo se induce la aprehensión cognitiva del estudiante espectador-lector hacia el desarrollo de subprocesos de análisis, generalización y síntesis, desde la percepción semiocinematográfica orientada por el docente, quien facilita que se produzca el discernimiento sígnico cuando el primero:

Ha identificado lo que está explicitado y lo que subyace de manera implícita en el texto cinematográfico.

Ha reconocido el sistema de signos que estructura el texto cinematográfico así como el que se privilegia. 
Establece relación título - contenido.

Percibe diferencias entre los ruidos naturales y artificiales (creados por la tecnología).

Advierte la significación de lo que se comunica a través de grafitis, vallas u otras notas escritas en diferentes superficies, en una llamada telefónica, las claves de conversaciones, los movimientos, el tratamiento del tiempo y del espacio, el empleo de los colores, la presentación del ambiente físico (natural o creado por el hombre) entre otros aspectos.

En lo antes expuesto queda expresado que de manera intrasubjetiva, el estudiante espectador - lector transforma y desarrolla su conocimiento y efectúa el discernimiento sígnico del texto cinematográfico como síntesis de las relaciones dialécticas entre la orientación procedimental y la percepción semiocinematográfica

Se asume entonces que para leer el texto cinematográfico, se debe reconocer como una representación en la que el referente de todos y cada uno de los significantes que lo construyen, puede existir o no en la realidad cotidiana. Tiene la particularidad de conmover e interesar a los sujetos y al mismo tiempo promover su imaginación desde sugerencias. El texto al que se alude, contiene una multiplicidad de microtextos que remedan lo que se denomina en Técnicas Narrativas "caja china" o sea se manifiesta en la posibilidad de construir un texto a partir de unidades mínimas en una sucesión que se prolonga hasta lo infinito, lo que obliga al estudiante espectador -lector a establecer vínculos internos en un juicio de comprensión exigente, juicio que tiene su génesis en el universo cognitivo cinematográfico, tanto del sujeto que enseña como del que aprende. Figueroa, E. (2007).

En síntesis, se está aceptando como texto cinematográfico aquel en el que confluyen idea e imagen audiovisual en un nivel de coordinación sintáctica que se da desde las 
secuencias, que no necesariamente transcurren en el tiempo real, que tiene una finalidad comunicativa, un cierre semántico y un carácter pragmático. Este texto, generalmente, se produce a partir de un guion y se construye con la intervención de un equipo de dirección, edición-producción y con carácter industrial. Debe ser observado-leído y escuchado atendiendo a sus códigos sonoro-visuales con la innegable presencia de la tecnología.

Desde esta perspectiva la lectura y comprensión del texto cinematográfico se constituye en un proceso a través del cual el sujeto que aprende va construyendo significados. Para ello, se vale de juicios conceptuales previos que corresponden al conocimiento acerca del mundo, es decir, los que el estudiante espectador-lector posee sobre el código audiovisual en particular y puede comunicar los plurisignificados del texto cinematográfico. Estos conocimientos pueden ser paratextuales (material de soporte, datos del autor, género, formato) y textuales.

En este trabajo, se está asumiendo como plurisignificados del texto cinematográfico:

Las diversas "lecturas" del texto cinematográfico que realiza, según su universo cultural, cada estudiante espectador-lector.

La percepción individual de la intencionalidad educativa que emerge de la orientación didáctica aportada por el docente.

La posibilidad de que cada estudiante espectador-lector decodifique no solo el contenido, sino, los elementos artístico- cinematográficos como otra dimensión del texto original, que trasciende lo artístico literario.

Este es el resultado de la cognición cinematográfica, la interacción cinematográfica, apuntan a considerar que se ha desarrollado el proceso de lectura y comprensión del texto cinematográfico como resultado de la orientación cognitiva y de interacción comunicativa en la relación sujeto-texto cinematográfico-sujeto-sujeto sujeto-grupo, en 
el que se demarca la proporción entre significados y significantes, aspectos que se concretan en la emisión de plurisignificados.

Por lo antes expuesto, en este trabajo se asume que el proceso de lectura y comprensión del texto cinematográfico transcurre cuando el docente (sujeto que enseña) orienta y guía, a través de claves semióticas, la relación objeto-sujeto-sujeto-sujeto y el estudiante espectador-lector (sujeto que aprende) lee y discierne lo que percibe en el texto cinematográfico desde lo individual, se prepara para el intercambio intersubjetivo.

Este proceso se orienta y dinamiza desde el método de comprensión cinematográfica plurisignificativa, método productivo en tanto admite el acceso a los procesos de análisis y síntesis al descubrir los diferentes microtextos que se hallan al interior del gran texto y que favorecen la obtención del mensaje cinematográfico de manera global.

El método de comprensión cinematográfica plurisignificativa tiene como característica esencial que compulsa el desarrollo de habilidades para la indagación acerca del texto cinematográfico objeto de recepción y lectura, en relación con el objetivo y los procedimientos, sin obviar el resto de los componentes del proceso de enseñanza aprendizaje.

Por otro lado, el método de referencia privilegia el establecimiento de la relación contextualizada con otros textos, orales, escritos, gráficos, icónicos, se orienta hacia la actividad del estudiante espectador-lector en interacción con el texto cinematográfico y con el resto de los sujetos participantes, promueve el trabajo colaborativo, tiene en cuenta las aproximaciones al texto cinematográfico desde todas las áreas del saber por su carácter pluridisciplinar.

Como parte de las acciones procedimentales, el estudiante espectador-lector, manifiesta sus experiencias, desde el intercambio, en diálogo reflexivo y abierto. En 
esas experiencias se tienen en cuenta la expresión de ideas, la confrontación de opiniones, entre otras formas de fomentar la construcción social del conocimiento en plena interactividad.

Entre las funciones del método de la comprensión cinematográfica plurisignificativa se hallan la:

Instructiva: Establece el contexto para la decodificación del texto cinematográfico.

Semiocognitiva: Permite que el estudiante espectador-lector reconozca el signo en sus diversas modalidades a partir de sus relaciones en el interior del texto cinematográfico y del acercamiento a la Semiótica, a la Psicología y la Lingüística del texto.

Interactiva-comunicativa: Responde el uso de códigos diversos a través de la comunicación de los plurisignificados y a su uso en diferentes situaciones y contextos de comunicación en constante interacción.

Sociocultural. Sienta las bases participativas del estudiante espectador-lector para que fluya la declaración de sus vivencias personales y contextuales, sobre las bases del respeto a la pluralidad de criterios.

Para la utilización del método se requiere partir del universo socio - cognitivo del estudiante espectador-lector de manera que este pueda aportar los plurisignificados relacionados con la génesis del texto cinematográfico que visiona, se debe aceptar el texto cinematográfico como una totalidad específica, pero que se le explora por partes dotadas de sentido, siempre estableciendo las relaciones del par contrario contenido forma así como de la identificación de sus códigos esenciales: idea-imagen cinematográfica y el contenido del texto debe contextualizarse al momento histórico en que ha sido creado desde sus nexos con el proceso histórico-social que representa y a la actualización en relación con las vivencias del estudiante espectador. 
En la declaración de los procedimientos didácticos se asume la necesidad de que se implementen actividades para la reflexión y el debate en los espacios de formación y en las variantes de talleres de lectura, en tanto desde esta actividad el método cobra toda su autenticidad. Se significa que los procedimientos, no solo deben ser enunciados, sino que deben orientarse secuencialmente, deben ser portadores de instrucciones; por su naturaleza operacional.

Los procedimientos del método se despliegan en acciones que desarrolla el docente en su condición de orientador y el estudiante espectador-lector como ejecutor. De acuerdo con las características del método planteado, su articulación se eslabona a partir de: la orientación explícita de la guía, significación de lo subjetivo y lo objetivo (como actividad práctica individual) y evaluación de la comprensión del texto cinematográfico (como actividad práctica colaborativa).

Este método es coherente con la propuesta de actividades que favorecen la lectura y comprensión de obras literarias y del texto cinematográfico y desde cada actividad a los participantes organizados, según se sugiera y de forma democrática, se le permite elaborar plurisignificados de forma oral o escrita: entre los que se sugiere el guion para un audiovisual y emitirán sus criterios acerca de cómo desean que quede la imagen audiovisual de su propio texto.

A partir de lo anteriormente expuesto, se toma como base orientadora lo planteado por la Doctora en Ciencias Filológicas, Beatriz Maggi quien al referirse a la relación cine-literatura ponderó el uso de la literatura o sea primero, la lectura, lo que se ha escrito en palabras; "eso hay que leerlo primero"1. Criterio con el que no se concuerda totalmente, mas se respeta, asumiendo que el cine es la creación magnífica de la imagen

\footnotetext{
${ }^{1}$ Comentario en el Curso de comprensión en Universidad Para Todos, coordinado por la Dra.C.Leticia Rodríguez. Curso que fue televisado en el año 2010 (Nota de autores)
} 
en movimiento y de hecho la versión cinematográfica puede ser mejor que el original que le sirvió de pretexto, en tanto el cineasta, leyó, investigó, transformó y explicó de manera creadora en un lenguaje diferente en el que se coordina imagen - sonido como síntesis audiovisual.

La evaluación, se concibe como proceso desde el primer momento en que se inicia el trabajo con la comprensión de textos audiovisuales. Se propone utilizar variantes de evaluación que compulsen a la comunicación intersubjetiva y con énfasis en el protagonismo de los participantes. Para tales efectos, se propone que el docente entregue una guía, previo convenio con el estudiante espectador-lector, y proponga los textos cinematográficos a utilizar en clases o en actividades extras.

Se sugiere que se privilegien, en principio, los textos cinematográficos, cuya esencia se halle en una obra artístico-literaria en soporte impreso de la literatura universal o nacional o que se relacione con hechos de la historia, biografía de personalidades de la historia de la humanidad o simplemente para la amplitud de la cultura del profesional de carreras con perfil pedagógico.

En principio se proponen como textos cinematográficos los que siguen:

- José Martí; el ojo del canario de Fernando Pérez.

En el canon literario desde la educación primaria hasta de la formación del docente de la carrera aludida es obligado el contacto con la obra abarcadora del Maestro y nada mejor que ilustrar con el texto cinematográfico referido que aborda aspectos trascendentales de su corta vida. Se incluyen varios textos en soporte digital y las sugerencias para la lectura y comprensión desde la mirada de la crítica autorizada y otros criterios acerca del gran texto. 
- Troya con la participación del célebre actor Brad Pitt en el papel de Aquiles La Odisea, Duelo de titanes (subtituladas) con el objetivo de ampliar el conocimiento acerca de los héroes homéricos y de la cosmovisión grecolatina, aspectos que se tratan en el canon literario del preuniversitario, esencialmente, en décimo grado.

- La bella del Alhambra de Pineda Barnet basada le obra literaria de Miguel Barnet, La canción de Rachel.

- Cimarrón; historia de un esclavo de Miguel Barnet y Juan Carlos Tabío. Este texto tiene la intención de ampliar los contenidos acerca del cimarronaje que desde el canon literario se tratan en los grados noveno y duodécimo con el cuento Los Fugitivos de Alejo Carpentier y El reino de este mundo respectivamente.

Desde la relación intertextual y contextual, se proyectan tareas que convergen con la visita al Monumento al cimarrón (texto icónico) en las lomas de las Minas del Cobre.

Se significa que para ampliar la cultura y saber más desde el testimonio, se orienta la lectura del libro Biografía de un cimarrón de Miguel Barnet sin el cual no es posible la comprensión cabal del texto cinematográfico (documental y presentación en la televisión cubana del mismo) y los textos cinematográficos Ciudad en rojo y Clandestinos, para establecer relación intertextual desde la lectura de la obra Bertillón 166 de Soler Puig.

Para reflexionar se atienden 10 claves para enseñar a interpretar, propuestas por Casany (s/f).

1. Trabaja la interpretación con todo tipo de textos.

2. Utiliza textos auténticos, del entorno del aprendiz o de sus temas de interés potencial.

3. Utiliza textos paralelos, opuestos o relacionados sobre un mismo tema 
4. Incluye textos multimodales.

5. Aprovecha las prácticas vernáculas previas (experiencias individuales).

6. Evita la respuesta única o la corrección convergente.

7. Fomenta el diálogo entre los alumnos.

8. Pregunta sobre el propósito y el punto de vista del autor

9. Fomenta la relectura y el análisis de los puntos relevantes.

10. Ayuda al alumno a relacionar la lectura con su mundo.

Finalmente, los autores sugieren atender las siguientes consideraciones: Leer y comprender un texto cinematográfico es un proceso activo y creativo de descifrar y decodificar la información que se presenta a través de la imagen sonora para reconstruir los significados. Según apuntó Pere Marqués (2000) significa saber interpretar significados, descubrir metáforas, analogías, leer una imagen sonora no significa únicamente identificar sus elementos morfológicos. El desconocimiento de las particularidades de este lenguaje (sintaxis y semántica, lectura y análisis crítico, composición de mensajes) deja al receptor de los mensajes audiovisuales pasivo ante los impactos emotivos que va recibiendo con las imágenes e indefenso ante su tremendo poder de seducción.

\section{Conclusiones}

La propuesta del método de comprensión cinematográfica plurisignificativa favorece el proceso de lectura del texto cinematográfico por parte del estudiante espectadorlector a partir de sus características y procedimientos.

El método propuesto es clave para diversificar la concepción que se tiene acerca de que la lectura es realizable solamente desde el código lingüístico.

El método es una ventana a la lectura del texto audiovisual en la sociedad hipermedial. 


\section{Referencias bibliográficas}

Barthes, R. (2004) Retórica de la imagen. Recuperado el 20 de abril de 2010 de http: / /www.avizora.com].

Eco, U. (2000). Tratado de semiótica. Barcelona: Editorial LUMEN

Cassany, D. Tras las líneas(s/f). Sobre la lectura contemporánea. Barcelona: Editorial Anagrama.

Figueroa Corrales, E. (2007). Una aproximación a las relaciones semióticas en una muestra de videoclases de Español- Literatura del preuniversitario. En resultados del proyecto de investigación: Comprensión de textos desde las clases y videoclases de español- literatura del preuniversitario.

Mateos, M. (2001). Metacognición y educación. Buenos Aires: Aique.

Rodríguez Pérez, L. (2010). Curso de comprensión en Universidad Para Todos. 